\title{
Perspectiva intercultural em práticas de formação de docentes indígenas
}

\author{
Tânia Ferreira Rezende ${ }^{1}$ \\ Eunice da Rocha Moraes Rodrigues ${ }^{2}$ \\ Universidade Federal de Goiás, UFG, Goiânia, GO, Brasil
}

Resumo: O objetivo deste artigo é discutir o estatuto do Português Intercultural, língua de relações interculturais, na licenciatura em Educação Intercultural da Universidade Federal de Goiás. Mais especificamente, visa-se discutir sobre como os docentes indígenas nas aulas de Português Intercultural estão significando e conceituando ideologias linguísticas coloniais, tais como linguagem, língua, escrita e padrão linguístico, transformadas em instrumento político de resistência em suas lutas cotidianas. A sustentação empírica são as práticas linguísticas orais e escritas de docentes indígenas, documentadas nas aulas de Português, em 2014 e 2015, e em publicações em livros e periódicos da área. A leitura dos textos é orientada pelos princípios do Paradigma Indiciário (GINZBURG, 2016), e a interpretação dos resultados é fundamentada nos pressupostos da Decolonialidade e pela concepção de língua como prática social. Os resultados mostram que o diálogo intercultural decolonial, nas relações de poder linguístico, não prescinde das estratégias de dominação das próprias forças dominadoras.

Palavras-chave: Decolonialidade; Interculturalidade; Formação de docentes indígenas; Português intercultural; Ideologia linguística.

Title: Intercultural perspective on indigenous teachers' education practice

Abstract: This paper aims to discuss the status of Intercultural Portuguese, language of intercultural relations, in the Intercultural Education degree course at the Federal University of Goiás. Specifically, it aims to discuss how indigenous teachers, in Intercultural Portuguese classes, are meaning and conceptualizing colonial linguistic ideologies, such as language, writing and linguistic pattern, transformed into a resistance political instrument in their daily struggles. The empirical support is the oral and written linguistic practices of indigenous teachers, documented in Portuguese classes, in 2014 and 2015, and in publications in specialized books and periodicals. The reading of the texts is guided by the principles of the Evidential Paradigm (GINZBURG, 2016), and the interpretation of the results is based on the assumptions of Decoloniality and the conception of language as a social practice. The results show that the decolonial intercultural dialogue, in the relations of linguistic power, does not dispense with the domination strategies of the dominating forces themselves.

Keywords: Decoloniality; Interculturality; Indigenous teachers' education; Intercultural Portuguese; Linguistic ideology.

\footnotetext{
1 Doutora em Linguística (Universidade Federal de Minas Gerais), Faculdade de Letras, Universidade Federal de Goiás, Goiânia, Goiás. Orcid: http://orcid.org/0000-0003-3954-2758. E-mail: taniaferreirarezende@gmail.com

2 Mestranda em em Performances Culturais da UFG. Professora na Escola Estadual Indígena Cacique José Borges, Terra Indígena Carretão (GO). Orcid: http://orcid.org/0000-0001-8829-3749. E-mail: eunicetapuia@hotmail.com
} 


\section{Introdução}

A escrita alfanumérica, em sua tecnologia e concepção ideológica ocidentalizadas, entrou na América com a colonização, no século XVI, ou seja, com a própria invenção da América, por meio da escola clerical, sob as ideologias do monolinguismo, da pureza e da correção linguísticas. Nesse período (e até recentemente), as línguas e os conhecimentos dos povos indígenas não foram reconhecidos, portanto, não tiveram lugar na escola. A escolarização dos indígenas foi um projeto de apagamento de sua ontoepistemologia e as línguas de colonização (línguas de civilização, línguas de cultura) cumpriram o papel de extermínio das línguas, dos conhecimentos e das culturas ameríndias (NEUMANN, 2015). Com esse processo, construiu-se a narrativa de justificação da subordinação dos povos e com eles de suas culturas, línguas e epistemologias indígenas nos territórios colonizados.

Atualmente, depois de séculos de conflitos, perdas, lutas e resistências, os indígenas vêm conquistando o direito à educação intercultural e bilíngue, para manutenção de suas línguas, epistemologias e culturas originárias. No Brasil, com a Constituição Federal de 1988 e a Lei de Diretrizes e Bases da educação nacional de 1996 (Lei 9.394), foi garantido aos indígenas o direito à educação diferenciada, com ensino na sua própria língua e respeito aos seus processos próprios de aprendizagem (suas epistemologias). Nesse movimento, foram criadas licenciaturas interculturais bilíngues, em diferentes regiões do país, para a formação de docentes indígenas. $O$ objetivo dessas licenciaturas é atender às demandas da educação escolar indígena, escutando e considerando o próprio indígena.

Assim é que foi criada, em 2006, a licenciatura intercultural de formação de professores indígenas da Universidade Federal de Goiás com início de suas atividades em 2007. Uma das demandas dos docentes indígenas dessa licenciatura foi pela formação também em português. Por isso, a importância de pensarmos sobre o estatuto do Português Intercultural, concebido como língua de relações interculturais na formação dos docentes indígenas, objetivo deste trabalho.

Nesta discussão, o ponto de partida são os significados que o português adquire na formação de uma intelectualidade indígena situada na diversidade sociolinguística brasileira. Tal diversidade, entendemos, é dominada pela língua portuguesa, o idioma oficial e a língua de cultura da nação. Entendemos também que sócio-historicamente, a língua portuguesa é idealizada nas ex-colônias portuguesas em sua soberania, pureza e correção.

Com a problematização proposta, pretendemos refletir sobre como os docentes indígenas em formação na licenciatura em Educação Intercultural da Universidade Federal de Goiás estão se apropriando de ideologias linguísticas coloniais, tais como língua, linguagem, escrita e padrão linguístico. Nosso objetivo é discutir comos os docentes indígenas, a partir de seu pluriverso de referências (MIGNOLO, 2017) e de seus repertórios conceituais particulares (KOPENAWA; ALBERT, 2015), estão significando e conceituando essas ideologias linguísticas. Nossa hipótese é que o português, para os docentes indígenas, é mais uma base de resistência política e de fortalecimento de suas lutas cotidianas. 
A sustentação empírica desta discussão são os conhecimentos construídos e compartilhados nas práticas linguísticas orais e escritas dos docentes indígenas, documentadas durante as aulas de Português Intercultural da licenciatura em Educação Intercultural da Universidade Federal de Goiás, em 2014 e em 2015, e nos artigos dos professores indígenas publicados nos livros e nos periódicos organizados pela licenciatura em Educação Intercultural da Universidade Federal de Goiás. A leitura das narrativas, das orais e das escritas, segue os princípios do Paradigma Indiciário Semiótico, de Carlo Ginzburg (2016), segundo o qual, muitas vezes, os "detalhes" indicam mais que as totalidades e o que está "ocultado" é de vital importância para a compreensão dos significados.

A interpretação e discussão dos resultados estão fundamentadas nos pressupostos da Decolonialidade, visando acessar as memórias para "desocultar" os saberes ocultados pela modernidade colonial (QUIJANO, 2010; MIGNOLO, 2007) e interpretar os sentidos que os sujeitos situados na diferença colonial estão construindo para os conceitos da modernidade/colonialidade. Consideramos, ainda, a concepção de linguagem como prática social (HANKS, 2008) e como uma invenção ideológica (MAKONI; PENNYCOOK, 2005; PENNYCOOK, 2010), nesse caso, situada na modernidade/colonialidade.

Com base nos resultados desta discussão, entendemos que o tenso e conflituoso diálogo intercultural, nas relações de poder linguístico, não prescinde das estratégias de dominação das próprias forças dominadoras.

\section{A licenciatura em Educação Intercultural da Universidade Federal de Goiás}

As licenciaturas interculturais de formação de docentes indígenas, fundamentadas na concepção bilíngue e intercultural de educação, surgiram no Brasil com a promulgação da Constituição de 1988 e, principalmente com a Lei de Diretrizes e Bases da Educação Nacional de 1996 (Lei 9.394). Nessa legislação, foram garantidos aos povos indígenas o direito à educação em suas línguas maternas e o respeito aos seus processos próprios de aprendizagem. Com essas concepções foi criada e implementada a licenciatura em Educação Intercultural da UFG.

A licenciatura em Educação Intercultural da UFG foi autorizada a funcionar em 2006 e iniciou as atividades em janeiro de 2007, com 59 estudantes dos povos Karajá, Karajá do Norte/Xambioá, Javaé, Gavião, Xerente, Tapuia, Guarani e Tapirapé (ROCHA; PIMENTEL DA SILVA; BORGES, 2010).

O curso está estruturado em dois eixos: sustentabilidade e interculturalidade, em três princípios pedagógicos: interculturalidade, bilinguismo e transdisciplinaridade, em uma matriz básica e em três matrizes específicas: ciências da cultura, ciências da natureza e ciências da linguagem. $O$ projeto de curso da licenciatura se desenvolve por meio de temas referenciais, temas contextuais, estudos complementares, estágios pedagógicos, pesquisa, iniciação científica e prática como componente curricular. 
Dada a concepção de educação bilíngue, intercultural e transdisciplinar, na licenciatura em Educação Intercultural são considerados, antes de tudo, os projetos societários dos povos indígenas em formação. Por sua concepção transdisciplinar, nesse curso, a educação bilíngue e intercultural "[...] incide na construção de pontes que entrelaçam dialogicamente as diferentes culturas e modos de conhecimento, afirmando a importância das suas peculiaridades, mas apontando para os seus nexos de complementaridade" (PIMENTEL DA SILVA, 2010, p. 13).

As línguas são concebidas como epistemologias, isto é, como conhecimentos específicos e como saberes mais amplos, tais como cosmologia, cosmovisão, ciências, artes etc. (PIMENTEL DA SILVA, 2010). As línguas indígenas, nesse projeto, são línguas de estudo no curso, os professores em formação fazem a documentação e o estudo de suas línguas - e línguas de ensino, quando necessário, com a mediação do português, sobretudo, nas etapas de estudos na UFG. O português é concebido e ensinado como língua de relações interculturais (língua de ensino e língua ensinada). O objetivo do Português Intercultural é, dentre outros, estabelecer interações e relações entre os diversos povos indígenas e entre os indígenas e os demais brasileiros, seus descendentes ou não, denominados "não indígenas".

Assim, o Português Intercultural, como componente do projeto do curso de Educação Intercultural, é um estudo complementar integrante da matriz básica e de todas as matrizes específicas, perpassando toda a formação docente dos indígenas em formação na licenciatura em Educação Intercultural da UFG. A expectativa dos estudantes é a de que eles possam se apropriar da escrita em português para atender às demandas de suas respectivas comunidades, não só as escolares, mas também todas as outras que exigem a prática social da escrita, conforme mostram os excertos (1), (2) e (3):

(1) [...] eu quero aprender língua portuguesa para elaborar o documento oficial, ofício, carta, bilhete, aviso, música etc. e também para me defender. Mandar para não indígena compreender melhor e gostar. (Não Identificado - A. Relatório de Aula, 2014)

(2) Desde que eu me interessei sobre a língua português eu vim tentando falar correto sem ter [ilegível] na minha fala português, tentando escrever correto. (Não Identificado - B. Relatório de Aula, 2014)

(3) Nessa oportunidade, ressaltar que a aula na próxima seja mais focado na explicação de regra ortográfica e de gramática, como exemplos na concordância quando elabora uma frase. (Não Identificado - C. Relatório de Aula, 2014)

A construção e o compartilhamento de conhecimentos

Entendemos que 'aula' é um acontecimento em que diversos saberes são socializados, entram em interação e são compartilhados. Nesse compartilhamento de 
saberes em interação, acontece a construção de outros ou novos saberes. Assim aconteceram as aulas de Português Intercultural de que tratamos.

Para esta discussão, são considerados os conhecimentos compartilhados pelos professores participantes da ação em suas práticas escritas na licenciatura em Educação Intercultural da Universidade Federal de Goiás nas aulas de Português Intercultural em 2014 e 2015. Nem todos os docentes que participaram das aulas participaram da pesquisa, cedendo suas práticas orais e escritas documentadas. A participação na pesquisa, da entrada e permanência à finalização das atividades, ocorreu por livre adesão, conforme as determinações da Resolução CNS 466/2012, acatada pelo CEP/UFG ${ }^{3}$.

A primeira turma de Português Intercultural com a qual trabalhamos era composta de professores Tapuia, Akwẽ (Xerente) e Pyhcop Cati-Ji (Gavião); a segunda turma era constituída de 9 povos diferentes: Akwẽ (Xerente), Apinayé (Apinajé), Apyãwa (Tapirapé), Iny (Karajá e Xambioá), Itya Mahãdu (Javaé), Krahô, Pyhcop Cati-Ji (Gavião) e Tapuia; a terceira turma era formada pelos A'Uwẽ (Xavante) e pelos Akwẽ (Xerente).

O quadro com as informações sociolinguísticas dos professores participantes das práticas linguísticas documentadas entre 2014 e 2015, que possibilitaram as reflexões constantes desta discussão, é como segue:

Quadro 1 - Declaração sociolinguística dos professores participantes da pesquisa

\begin{tabular}{|c|c|c|c|}
\hline \multirow[b]{2}{*}{ Povo } & \multicolumn{2}{|c|}{ Filiação linguística } & \multirow{2}{*}{$\begin{array}{l}\text { Localização } \\
\text { geopolítica }\end{array}$} \\
\hline & Grupo & Família & \\
\hline Akwẽ (Xerente) & Macro-Jê & Jê & Tocantins \\
\hline Apyãwa (Tapirapé) & Tupi & Tupi-Guarani & Mato Grosso \\
\hline Apinayé (Apinajé) & Macro-Jê & Jê & Tocantins \\
\hline A'uwẽ (Xavante) & Macro-Jê & Jê & Mato Grosso \\
\hline Krahô & Macro-Jê & Jê & Tocantins \\
\hline Krẽka (Xakriabá) ${ }^{4}$ & Macro-Jê & Jê & Minas Gerais e Tocantins \\
\hline Iny (Karajá/Xambioá) & Macro-Jê & Karajá & Tocantins \\
\hline Itya Mahãdu (Javaé) & Macro-Jê & Karajá & Tocantins \\
\hline Pyhcop Cati-Ji (Gavião) & Macro-Jê & Jê & Maranhão \\
\hline Tapuia & Macro-Jê & Jê & Goiás \\
\hline
\end{tabular}

Fonte: elaboração das autoras a partir das informações declaradas pelos professores participantes.

As informações apresentadas no Quadro 1 foram declaradas pelos estudantes e representam suas percepções sobre sua filiação linguística e seu pertencimento étnico. Equivale a dizer que o modo de referenciação de cada povo, de cada língua, cultura, conhecimento, conforme sua autodeclaração, foi solicitado, indicado e informado pelos

\footnotetext{
${ }^{3}$ A pesquisa, cujos resultados parciais ora são relatados e discutidos, está vinculada ao projeto Atitudes sociolinguísticas e posturas políticas balizadoras das práticas escritas nas aulas de Língua portuguesa, cadastrado no sistema de gestão de pesquisas da UFG, foi submetido ao Comitê de Ética em Pesquisa da UFG, obtendo aprovação vigente de 2014 até dezembro de 2017 sob o número CEP/UFG 790.006.

${ }^{4}$ A professora Krẽka, de Minas Gerais, encontra-se morando com os Akwẽ, no Tocantins.
} 
docentes participantes. Essa decisão representa uma postura política coerente com a atual atitude sociolinguística dos povos indígenas e com a opção decolonial adotada nas aulas de Português Intercultural.

Os professores participantes das construções e compartilhamentos de saberes declararam ter a língua indígena como sua primeira língua e o português como a língua outra para as relações interculturais. Independentemente da situação e das condições da aquisição, a língua indígena é assumida e defendida como a língua materna por todos eles, até mesmo para aqueles que têm o português como primeira ou como única língua, porque, repetimos, a questão é política. Há algumas situações que merecem destaque, por sua singularidade frente às demais do curso, que serão levantadas posteriormente.

\section{Procedimentos adotados}

Conforme explicado anteriormente e conforme pudemos constatar com os resultados da pesquisa, na licenciatura em Edcuação Intercultual da UFG, nas nossas aulas de Português Intercultural, o tempo todo, há compartilhamento e construção de saberes. As aulas se desenvolvem por meio de pesquisas, estudos sobre resultados de pesquisas, sobre reflexões teóricas e, sobretudo, acerca das reflexões dos docentes indígenas. Dessa forma, a licenciatura se desenvolve, é avaliada e repensada continuamente.

No Português Intercultural, que é um componente básico de todas as matrizes do curso, conforme já explicado na introdução da seção intitulada "A licenciatura em educação intercultural da Universidade Federal de Goiás", partimos da ementa e do tema contextual previstos para cada etapa de estudo ${ }^{5}$ e construímos, coletivamente, o programa, discutindo sobre as estratégias e selecionando o material de estudo no início da etapa, também em conjunto. Algumas atividades são recorrentes em todas as etapas, como o Memorial da trajetória sociolinguística e o Relatório de Aula. O Memorial é uma narrativa pessoal sobre as vivências sociolinguísticas dos indígenas, principalmente no que diz respeito à sua relação com o português e com a escola. Essa narrativa é produzida na oralidade e na escrita ${ }^{6}$ e pode ser ou não identificada. O Relatório de Aula, por ser autoavaliativo ou avaliativo das aulas de Português Intercultural, da etapa de estudos na UFG e até mesmo do curso como um todo, não é identificado. Os materiais identificados, nesta discussão, recebem nomes fictícios para preservar a identidade dos professores. Todavia, procuramos manter a estrutura de identificação que está posta nos textos.

Em um primeiro momento, o Memorial é narrado oralmente, em roda de conversa. Nessas práticas narrativas orais, predomina o translinguajamento, baseado em Gloria Anzaldúa (2012). A autora distingue "bilinguajar", habitar e viver em mais de uma língua, de

\footnotetext{
${ }^{5}$ Matriz curricular do curso disponível em: https://intercultural.letras.ufg.br. Acesso em: 26 set. 2020.

${ }^{6} \mathrm{O}$ enunciado "Essa narrativa é produzida na oralidade e na escrita" e não "narrativa produzida oralmente", por exemplo, significa que a oralidade e a escrita são lóci de narração, são lugares de encontros e interações interculturais e de compartilhamentos de saberes e sentimentos, e são espaços políticos, mais que modos de narrar.
} 
"bilinguismo", que é a habilidade, a instrumentalização de usar mais de uma língua, que pode ocorrer pela aprendizagem sem que a pessoa habite e viva nas línguas aprendidas. No bilinguajamento, as línguas vivem e convivem, interagem, se cruzam, entram em confronto, em conflito, e continuam convivendo, porque não há convivência sem confronto e conflito.

Na visão binária da universidade monoglóssica, há uma hierarquia de sentidos e do dizer os sentidos: uma só voz e um só dizer válidos na enunciação de um só sentido legítimo. Para além da universidade monoglóssica, numa perspectiva não binária de ver o mundo, a dialogia entre línguas, concebida na pluriversidade (MIGNOLO, 2017), está além da diglossia, é heteroglóssica: as vozes, os sentidos e os dizeres existem em pluralidade e em disputa. Assim, na tentativa de superar os binarismos (di/bi), adotamos translinguajamento, entendido como "falar-pensar-sentir-agir" entre línguas (ANZALDÚA, 2012) em travessia, em trânsito (LIMA, 2020). Por isso, as narrativas são narradas em Português translinguajando com as línguas indígenas. $O$ translinguajamento, nessa concepção, não diz respeito somente à interação entre as línguas (léxicos, fonologias, gramáticas), é também epistêmico.

Posteriormente, o Memorial é narrado na escrita. Nesse segundo momento, os professores são livres para escolher em que língua preferem escrever suas narrativas. Se narrarem primeiro na língua indígena, devem, depois, traduzir para o português, que é a língua de estudo, e porque a professora coordenadora do estudo não conhece as línguas indígenas. Com essa liberdade de escolha, mesmo com a limitação imposta pela necessidade da escrita em português, eles continuam praticando o translinguajamento (LIMA, 2020). O resultado são conhecimentos escritos em português, numa escrita em português prenhe de palavras, significados e sentimentos da língua indígena. Em outras palavras, não significa aqui uma "escrita indígena", genericamente. São conhecimentos escritos em português num pensar-agir-sentir entre línguas situado, particularizado: Akwẽ, Apyãwa, Apinayé, A'uwẽ, Krahô, Krẽka, Iny, Itya Mahãdu, Pyhcop Cati-Ji, Tapuia.

Entre os Tapuias, a escrita é praticada no "Português Tapuia" (REZENDE, 2011; RODRIGUES-TAPUIA, 2011; 2018) e ocorre nas atividades descritas anteriormente, nos relatórios de estágios e de pesquisa, que também são considerados nesta discussão. Para Rezende (2011) e para a professora Tapuia Eunice Rodrigues-Tapuia (2011; 2018), o Português Tapuia é a língua de significação de um mundo ao qual pertence o indígena Tapuia do Carretão. É nessa língua que eles pensam, sentem, sonham e agem no mundo. É nessa língua que eles comunicam seu mundo ao mundo e é nessa língua que eles escrevem, no Carretão e na universidade. O translinguajamento não está excluído das práticas sociolinguísticas do Tapuia nem é menos complexo que nas práticas sociolinguísticas dos demais povos indígenas, como o concebe a visão monoglóssica binarista de mundo. Assim, as práticas escritas dos Tapuia levantam uma questão fundamental: na perspectiva da pluriversidade (MIGNOLO, 2017), qual o sentido de uma norma escrita? 


\section{Opções teóricas}

A modernidade/colonialidade inventou a América sustentada na ideologia da pureza de sangue e de raça/cor, no controle do gênero/sexualidade, dos corpos, do trabalho e das classes (QUIJANO, 2010; MIGNOLO, 2003; 2007; 2017). A América inventada foi situada às margens do centro do geopoder mundial dominado pela Europa/pelo ocidente. Mais tarde, depois da Segunda Guerra Mundial e, mais forte ainda, com o fim da Guerra Fria, os Estados Unidos da América passaram a integrar o centro do geopoder, expandindo-se o "ocidente" para a Norte América anglo-saxônica.

Nesses movimentos, instituiu-se um poder linguístico, primeiramente por três línguas (espanhol, português e italiano), entre o Renascimento e o lluminismo, ampliado para seis línguas, com a entrada das línguas alemã, francesa e inglesa para o centro de dominação, a partir do lluminismo (MIGNOLO, 2003). Com a expansão do "ocidente", as línguas portuguesa e espanhola perderam em importância, por não se sustentarem como línguas de produção e veiculação de conhecimento. Os povos ameríndios, africanos e asiáticos permaneceram subalternizados, à margem (ou borda) do centro de poder e, da mesma forma, continuaram também suas línguas e seus conhecimentos.

Na modernidade/colonialidade, o ocidente, ou primeiro mundo, e sua contraparte, a América Latina, ou terceiro mundo, diferenciados pela pureza de sangue e pela raça/cor, formam lóci de enunciação ambivalentes, em confronto, a partir dos quais se avaliam e conceituam os povos, as línguas e os conhecimentos em circulação no mundo. É nesse contexto que entendemos que as línguas, as culturas, os conhecimentos e as raças, como categorias hierarquizadas, são invenções subalternizadoras dos povos situados nas margens do centro de poder (SPIVAK, 2010), tais como os ameríndios.

A codificação da diferença entre o eu/nós, os grupos em posição de poder, e o outro, os demais, tendo como critério "a ideia de raça", segundo Quijano (2010), é uma "construção mental", isto é, o racismo, que fundamenta uma "racionalidade específica", o eurocentrismo. Com essa racionalidade específica fundamentada em tal construção mental, o homem da modernidade/colonialidade subalternizou os povos, as línguas, as espiritualidades e os conhecimentos do, para eles, recente "Novo Mundo".

Os povos subalternizados, de acordo com Mignolo (2003) e Spivak (2010), são os sujeitos situados às margens do geopoder mundial e, mesmo nessas margens, são os sujeitos das camadas marginalizadas, os excluídos dos meios de acesso aos bens e serviços básicos, excluídos do mercado de trabalho ou relegados aos subempregos e às baixas remunerações (controle do trabalho); são os impedidos de participar das representações políticas e das esferas de tomadas de decisão (controle das classes). Para esses povos, as categorias: 'linguagem', 'língua' e 'conhecimento', assim como as subcategorias hierarquizadoras 'língua de civilização', 'língua de cultura', bem como suas contrapartes 'dialeto' e 'crioulo', incluindo as mais recentes 'primeira língua', 'segunda língua', 'língua 
materna', 'línguas adicionais' etc. são as ideologias linguísticas de que tratamos nesta discussão, entendidas como invenções subalternizadoras.

A partir dessas categorias e subcategorias, foram definidas as línguas de legitimação e veiculação do conhecimento e foram estabelecidos os "conhecimentos racionais" como forma de estruturação da vida dos povos ameríndios. Em um universo de povos de culturas orais, os conhecimentos legítimos foram definidos como aqueles documentados nas "línguas de cultura", por meio da "escrita alfanumérica ocidentalizada", sob a ideologia da "pureza" e da "correção" linguísticas. Ancorado nessas ideologias, o projeto moderno/colonial de nação e de sociedade constrói outra ideologia, a homogeneidade sustentada pela pureza linguística, cultural e epistêmica, construídas pela escola, defendidas e exigidas pela sociedade.

O padrão linguístico escrito da língua de cultura, utilizado pela minoria social culta, é definido como "o padrão linguístico" a ser seguido por todos (universalização do particular). Equivale a dizer que a tradição linguística criada, que se converteu em capital simbólico, cujo prestígio é atribuído à língua, tem sua origem no poder de decisão do grupo dominante (HANKS, 2008). A partir daí, opera-se o epistemicídio (GOMES, 2018) por meio do linguicídio (REZENDE, 2015).

Em síntese, "[n]o mundo moderno, a razão e o saber pressupunham a pureza e a gramática de uma língua, e, sem mencionar o fato, a epistemologia se entrelaçou com as ideologias nacionais" (MIGNOLO, 2003, p. 341). Na América Latina, portanto, "negar que escrevemos [falamos, pensamos e sentimos] como povos, cuja consciência foi formada como sujeitos coloniais, [seria como] negar nossa história" (MIGNOLO, 2003, p. 239). 0 desafio, na América Latina, é defender o direito de existir dessa consciência, como o pensamento outro da colonialidade, subalternizado pela colonização, tanto quanto as línguas e os povos ameríndios. Da mesma forma, defende-se o direito à língua colonizadora, significada e conceituada a partir do entendimento do que seja língua para os povos ameríndios, concebida como língua de relações interculturais, na perspectiva do translinguajamento. Essa seria uma maneira de enfrentar as ideologias do monolinguismo e da homogeneidade. Os enunciados (1)-(3), citados na subseção precedente, refletem as ideologias coloniais discutidas aqui, mas na perspectiva da diversidade linguística.

Assim, a partir de uma opção decolonial e de um projeto de desinvenção das categorias inventadas pela modernidade colonial, os ameríndios são abordados como povos subalternizados pela modernidade colonial, marcados pelas feridas coloniais. O objetivo primordial dos estudos, nessa linha, é contribuir com o deslocamento dos subalternizados da condição de subalternidade.

Dessa forma, nesta discussão, tendo a América Latina como lóci pluriversos de enunciação, os indígenas são abordados como sujeitos subalternizados pela modernidade colonial, mas não como inferiores; assim, são abordados em uma perspectiva de estudo e não como um objeto ou uma categoria de análise. São sujeitos, professores, intelectuais, que constroem e compartilham seus conhecimentos. 


\section{Desinventando as ideologias coloniais}

Nesta seção, nos dedicamos a refletir sobre o estatuto do Português Intercultural, concebido como língua de relações interculturais, na licenciatura em Educação Intercultural de formação de docentes indígenas da Universidade Federal de Goiás. Nosso objetivo é discutir sobre como esses docentes indígenas estão se apropriando, significando e conceituando as ideologias coloniais, tais como linguagem, língua, escrita e padrão linguístico, entendidas como políticas de resistência linguística, em suas lutas cotidianas.

Para tanto, partimos das percepções de língua/linguagem, escrita e padrão linguístico dos docentes indígenas. Com base no Paradigma Indiciário, conforme já informado, a interpretação da escrita dos textos tem como pistas os conhecimentos compartilhados em suas próprias práticas escritas. Com isso, buscamos entender como esses docentes indígenas estão conceituando linguagem, escrita e padrão de escrita em português (norma).

Percepção dos indígenas sobre linguagem, língua e padrão linguístico

Com base na interpretação dos conhecimentos compartilhados nas práticas orais e escritas de licenciados e licenciandos do curso de Educação Intercultural da UFG, é possível acessar suas percepções sobre linguagem e línguas, sobre língua portuguesa, sobre escrita, escrita em português e sobre padrão linguístico e escrita padrão em português (norma).

Como ponto de partida para a discussão, foram selecionados três enunciados retirados de diferentes práticas escritas:

(4) Na escola, já com 15 anos de idade, sem entender nada do que a professora explicava, eu não falava português, eu não sabia escrever nem ler, e ela escrevia no quadro, aquele tanto de letra, e explicava naquela língua e eu não entendia. E eu fiquei pensando... e agora como eu vou fazer pra me virar nesses dois mundos, aqui dentro da minha cabeça?! (MAIRU-KARAJÁ, 2012, apud REZENDE, 2015, p. 73)

(5) [...] Além disso, vimos a estrutura de cartas oficiais e não oficiais, como tanto no ofício, requerimento, ata, que me levou a me motivar mais conhecer o mundo do tori $^{7}$, a aprender mais, porque no futuro a gente possa buscar o nosso direito para a aldeia através desse documento oficiais e não oficiais, então, para mim foi um grande avanço nesse sentido. Porque, no meio do não indígena a gente se sente insegura. Isso deixa a gente com autonomia e segurança, na hora de buscar alguma coisa. (Não identificado-D. Relatório de Aula, 2014)

(6) A Língua Indígena Xerente é uma estrutura da comunidade, por tão importante para a organização do povo Indígena Akwẽ. É importante para cada dia se comunicar, na oralidade, como têm bastante evoluído nas comunidades, pois as comunicações são

\footnotetext{
7 "Tori" significa "não indígena” em inyrubé, a língua dos Iny (Karajá).
} 
através de grito, de choro, de cântico, de sorrir, de conversa e também de outra maneira. (PRUNÕTRI-AKWẼ, C. Concepção de Linguagem, 2015)

(7) A reprodução deste trabalho de escrita é uma forma de sustentabilidade cultural do povo Akwẽ Xerente sobre o aproveitamento de plantas frutíferas do cerrado como: bacaba (kakrã), buriti (pizu), caju (mkoitorã), mangaba (krito), pequi (kbarê), puçá (tinni), oiti (wdêkrãikwasa), buritirana (ware), murici (kunêrê smikre rê) etc. (KUMRIZDAZÊ XERENTE, C. Práticas Pedagógicas, 2015, p. 153)

A percepção desses autores é de língua/linguagem como comunicação e interação, como parte constitutiva do povo, como atravessamento e como conhecimento e sentimento, emoção. Para eles, línguas são "mundos" que os habitam e constituem, em atravessamentos e trânsitos, as travessias, como em (4): "e agora como eu vou fazer pra me virar nesses dois mundos, aqui dentro da minha cabeça?!", e em (5): "que me levou a me motivar mais conhecer o mundo do tori".

Lima (2020), discutindo os conhecimentos dos surdos em suas práticas escritas em português, conceitua as travessias entre mundos pelas práticas sociolinguísticas em português das pessoas surdas. Seus resultados corroboram a teoria de Anzaldúa (200; 2012) sobre "viver entre línguas" (translinguajamento). Os conhecimentos enunciados em (4) e (5) sobre o se "virar entre mundos", os mundos Iny e tori, corroboram o viver entre línguas, habitando mais de um mundo, de Anzaldúa.

Nos encontros, nos espaços de translinguajamentos, o "me virar nesses dois mundos" é o que entendemos por prática de travessia sociolinguística. Os "mundos" são línguas, entendendo-se, com base em Pimentel da Silva (2010), já mencionado, que língua, cultura e conhecimento são indissociáveis, por isso, constituem um mundo a se conhecer e a se habitar.

Em (6), o conceito de linguagem/língua é abrangente, envolve o corpo todo, todos os sentidos, os sentimentos e toda forma de expressão. Apesar disso, não equivale à língua como totalidade ou como universalidade, no sentido moderno/colonial. Trata-se de ver a língua como mais que instrumento de comunicação, mais que emissão sonora e mais que enunciados abstratos. É a linguagem como enunciação histórica, cultural, social e política.

Em (7), língua é conhecimento, é simbolização do mundo pela flora, é espaço de luta e relação de poder; pode-se perceber a disputa de espaço entre as línguas Tupi e Akwẽ, por meio da nomeação dos frutos do cerrado, uma luta da qual o português, língua majoritária, não participa. O espaço de translinguajamento aqui se forma na interação entre as línguas Tupi, que ganharam força e poder pela apropriação colonial durante o período de dominação portuguesa, e a Akwẽ, de fundamental importância e com poder local ao lado do português ${ }^{8}$.

Retomando os enunciados (4) e (5), é possível perceber o sentido que os indígenas constroem para sua realidade sociolinguística: em (4), pode-se perceber a preocupação com

\footnotetext{
${ }^{8}$ Lei municipal sancionada em 2012 dispõe sobre a cooficialização da língua Akwẽ-Xerente no município de Tocantínia, estado do Tocantins.
} 
o translinguajamento no pensar entre as línguas (ANZALDÚA, 2012), nos dois mundos, e na expectativa de habitar as línguas; em (5), a preocupação é com a apropriação do mundo do não indígena (o tori), mas não, necessariamente, em situação de habitá-la (ANZALDúA, 2012). O sentido de apropriação, em (5), pode ser percebido também com relação ao domínio da escrita em português: "vimos a estrutura de cartas oficiais e não oficiais, como tanto no ofício, requerimento, ata", e essa é a motivação para conhecer o "mundo" não indígena, para se apropriar da escrita, sobretudo da escrita oficial, para se defender no/do mundo do tori. Nesse enunciado, a escrita, na percepção da autora, é um instrumento de luta por e de defesa de direitos, uma percepção notada também em (7).

Ainda no enunciado (5), a autora, translinguajando em português/inyrubè/português, expressa sua insegurança no "meio do não indígena", o que antes era o "mundo do tori". 0 "conhecer" (o mundo desconhecido) está relacionado ao "mundo do tori", em que o não indígena é referenciado em inyrubè, sua língua materna, língua de conforto e segurança. Em seguida, o "mundo do tori" é substituído por "meio do não indígena", totalmente em português, ao mencionar o lugar da "insegurança" e a necessidade de apropriação da escrita em português, para sua defesa, como coletividade, nesse/desse "meio". A língua dessa referenciação é o português, a língua da insegurança e da subalternização.

A noção de padrão linguístico refletida nos enunciados (1)-(3) está, sem dúvida, relacionada à ideologia de correção linguística, mas não à ideologia de pureza, que sustenta o monolinguismo e a homogeneidade. A expectativa é de apropriação para independência com segurança - "eu quero aprender língua portuguesa para elaborar o documento oficial, ofício, carta, bilhete, aviso, música etc."; para persuadir e convencer - "Mandar para não indígena compreender melhor e gostar"; e como espaço de luta e defesa - "[...] e também para me defender" - Enunciado (1) -, porque o translinguajamento, diferentemente do que defende Mignolo (2003, p. 315) para o bilinguajamento, é uma questão política inscrita e refletida na gramática.

Até mesmo nos enunciados (2) e (3), que focam diretamente na norma, o sentido não é o de obedecer à norma por uma questão de pureza e correção linguística ou de autoridade nem de subjugação à língua portuguesa. Trata-se de perceber a língua como um campo de luta por espaço político entre indígenas e não indígenas e, ao mesmo tempo, como um instrumento que fortalece suas lutas políticas de enfrentamento ao poder constituído que os quer dominar e subalternizar.

Trata-se, enfim, da percepção da relação de poder que existe entre as línguas e entre os povos e, ao mesmo tempo, da consciência da importância de dominar a escrita na língua hegemônica. Os indígenas entendem que a apropriação da escrita em português é uma vantagem, por ser uma forma de fortalecimento político nesse campo de luta diária entre indígenas e não indígenas. Assemelham-se às discussões de Anzaldúa (2012) e de Lima (2020), mencionadas anteriormente. Nos enunciados (4)-(6), a escrita em português está na travessia entre os "mundos" indígenas e não indígenas, e, nesse lócus de enunciação, está 
refletida uma percepção positiva da escrita em português como instrumento que fortalece a luta por espaço político.

\section{E se o bilhete substituir o recado? Tensão entre oralidade e escrita}

Os povos indígenas manifestam preocupação com a entrada da escrita nas terras indígenas, principalmente com a escrita em português. Os Krahô estão engajados, há anos, em acaloradas discussões sobre o estabelecimento de uma só convenção escrita para todas as línguas timbiras. O descontentamento dos Krahô, compartilhado pelos Krikati e Gavião, advém do fato de a escrita de suas línguas estar sendo convencionada por "linguistas não indígenas", ainda que, muitas vezes, assessorados por professores indígenas, pois estes nem sempre são timbiras, e porque uma só convenção escrita para todas as línguas timbiras poderia, com o tempo, "tornar essas línguas diferentes em uma só ou deixar muito parecidas” (JÃXY-KRAHÔ, 2014).

No geral, as discussões orais e os relatos escritos dos docentes indígenas sobre escrita nas línguas indígenas e em português revelaram certa desconfiança por parte deles em relação à escrita, mostraram que eles vinculam a escrita à língua portuguesa e à cultura não indígena. A atitude dos docentes em relação à escrita destaca o grafologocentrismo, dentre as ideologias coloniais de que estamos tratando nesta discussão, como mostram os enunciados a seguir:

(8) Entre os Tapuia prevalece a oralidade, que é um "método simples", e a escrita na comunidade "pouco aparece". Há pouco tempo, cerca de uns 25 anos, que a escrita adquiriu importância na comunidade Tapuia. Antes disso, mesmo as reivindicações, que agora são feitas por escrito, eram feitas verbalmente. (BRANDÃO-TAPUIA, 2011. Concepção de Linguagem, destaques do autor, apud REZENDE, 2013)

(9) A comunidade tá preocupada com medo do bilhete substituir o recado (VIEIRATAPUIA, 2012)

(10) A contribuição de preservarmos o conhecimento na escrita é muito importante para o saber humano na visão ocidental, que "prioriza" documento escrito. [...] Que esse registro de documento sirva para não acabar os valores tradicionais do Akwẽ Xerente, que não podem ficar só oralmente. (KUMRIZDAZÊ-XERENTE, C. Práticas Pedagógicas, 2015, p. 153)

Há duas preocupações entre os indígenas: o fato de que no mundo do não indígena só vale o escrito - "o saber humano, na visão ocidental, que 'prioriza' documento escrito" (10); e o fato de a cultura escrita ameaçar a cultura predominantemente oral (9). Decorre dessas preocupações o "receio" do professor Tapuia de "o bilhete substituir o recado", entendendo-se que o recado é oral e o bilhete é escrito. Essa desconfiança se justifica, em parte, pelo que está enunciado em (8), que a escrita é uma prática recente e que está ainda adquirindo importância na comunidade, diante das novas demandas sociais. 
O enunciado (10) mostra de forma mais explícita que as mesmas novas demandas sociais que ameaçam as línguas indígenas despertam os indígenas para a importância da escrita na preservação de seus saberes tradicionais e no fortalecimento de suas línguas e de suas epistemologias. Eles têm percebido que, com a escola indígena e com a escrita também na língua indígena, a escrita pode ser uma importante aliada em suas lutas políticas. Essa discussão está mais bem desenvolvida a seguir.

\section{A escrita é o backup e a oralidade é o updating da língua}

De forma geral, nas aulas de Português Intercultural, predominam a pluriversidade e o translinguajamento (ANZALDÚA, 2012; MIGNOLO, 2017; LIMA, 2020) - as práticas linguísticas acontecem durante as aulas nas línguas dos indígenas o tempo todo: os professores em formação são livres para cantar e dançar quando consideram pertinente. Os povos das diferentes línguas da família Jê (Macro-Jê) interagem entre si, cada qual com sua língua, e se entendem. A interação entre os vários Jê, os Karajá (Macro-Jê) e os Tupi-Guarani (Tupi) acontece em português. Todos falam com a professora e com os monitores em português. Além disso, os conhecimentos construídos e compartilhados em outros estudos complementares e nos temas contextuais que eles estudaram ou que estivessem estudando no momento das aulas de Português Intercultural, se fossem compartilhados nas aulas, eram acolhidos.

Foi assim que em 2014, uma parte da turma que havia terminado as aulas de informática, durante as aulas de Português Intercultural, transpunha para as discussões as terminologias do campo da informática. Isso gerou muito riso. Numa das rodas de conversas, a metodologia mais empregada nas aulas, enquanto discutíamos sobre o papel da escrita nos processos de mudança e na conservação linguística nas línguas indígenas, um deles perguntou se "a escrita poderia ser o backup da língua" e alguém, do outro lado da sala, disse: "então, a oralidade deve ser o upgrade da língua", do que se seguiram muitos risos.

Uma estudante, que vinha da aula de Inglês Intercultural ${ }^{9}$, consultou o google pelo celular e perguntou o que era mais adequado, nesse caso: upgrade ou update? Discutimos os sentidos e os contextos de uso de cada termo e a turma toda se engajou na discussão, em diferentes translinguajamentos. Por fim, chegaram ao consenso de que update era mais adequado, porque toda língua muda e se atualiza, mas não no sentido de melhorar ou de aprimorar, ligando essa discussão com a imediatamente anterior sobre mudança linguística. Decidiu-se, então, que empregaríamos updating para expressar o sentido de atualização constante e contínua das línguas. Todos concordaram, tomando por base suas experiências com o computador e o celular. Essa é a prática do translinguajamento construída e compartilhada na pluriversidade.

\footnotetext{
${ }^{9}$ A perspectiva de ensino nas aulas de Inglês Intercultual é diferenciada e se fundamenta também na concepção de translinguajamento, diferente de bilinguismo, de bilinguajamento e de translanguaging. Para informações sobre Inglês Intercultural, na licenciatura em Educação Intercultural da UFG, remetemos a Cotrim (2017).
} 
As reflexões que os docentes indígenas relataram, posteriormente, por escrito, mostram um entendimento e uma tomada de posição frente à escrita em suas vidas, sustentadas pelo entendimento das funções de backup, upgrade, update e updating, que são conhecimentos construídos na Informática e trazidos para o Português Intercultural, com o suporte da língua inglesa. Essas reflexões foram relacionadas novamente às discussões sobre mudança linguística, os processos de mudança, as mudanças em cadeia, se há ou não mudanças por ruptura ou abruptas. Esse entendimento foi sistematizado em discussões realizadas nas línguas dos povos Akwẽ, Apinayé, Apyãwa, Tenetehara/Guajajara, Iny, Itya Mahãdu, Krahô, Krahô-Kanela, Kricatijê, Pykopjê e Tapirajá (Apyãwa e Iny), e em português, além do inglês, que entrou na discussão pela prática, já comum nas aulas, do translinguajamento - pensar, falar, ler e escrever, transitando entre línguas, nesse caso, em meio a piadas e risos, porque "as comunicações são através de grito, de choro, de cântico, de sorrir, de conversa e também de outra maneira" (PRUNÕTRI-AKWẼ, 2015).

Com base nessa experiência e nos enunciados selecionados e citados a seguir, discutimos sobre a conceituação das ideologias coloniais pelos indígenas:

(11) [...] Porque o português é uma língua que consideramos como segunda língua. Por isso, eu tenho que aprender muito. O mais importante que a língua português é você escrever em forma correta. (Não Identificado - E. Relatório de Aula, 2014)

(12) Para eu entender mais desse tema fiz a pesquisa sobre a língua portuguesa, língua que sempre pensei que era inabalável, impossível de ser invadida por qualquer outra língua, porém através da pesquisa, entendi que o léxico de todas as línguas se renova. (LARIWANA KARAJÁ, Práticas Pedagógicas, 2015, p. 285)

(13) A língua nativa é fundamental para os povos Xavante para manter para sempre passando para gerações novas e daí surgindo novos falantes da nossa língua mesmo ocorre as mudanças na sotaque e gíria. (TSERERUOTZE'Õ, Concepção de Linguagem, 2015)

(14) A escrita é usada para apreender o algo que queremos e também ter o conhecimento adquirido para transmitir à geração que irá ter oportunidade de conhecer o que já passamos. (BRUPAHIDI-AKWẼ, Concepção de Linguagem, 2015)

O enunciado (11) mostra a apropriação das ideologias coloniais, como, por exemplo, da categoria "segunda língua", que dá ao português um lugar, um lugar secundário (que não se confunda com desimportante), na percepção indígena, ao mesmo tempo em que situa a 'norma' na 'escrita' dessa segunda língua - “O mais importante que a língua português é você escrever em forma correta”. Essa percepção pode ser inferida também nos enunciados (2) e (3). A norma e a noção de correção estão vinculadas à escrita na língua que inventou e que veicula a norma. Escrita e "língua padrão" estão vinculadas e pertencem ao sistemamundo (WALLERSTEIN, 1974) que as inventou.

Da mesma forma, a relação entre os enunciados (11) e (12) permite inferir uma percepção da língua portuguesa como correta, pura, inabalável, que vai se desconstruindo, à medida em que as metalinguagens e as ideologias coloniais vão sendo desinventadas 
(MAKONI; PENNYCOOK, 2005). Com o abalo das metalinguagens e a desinvenção das ideologias coloniais, a língua portuguesa vai ficando no mesmo patamar das línguas indígenas, porque a importância das línguas indígenas vai aumentando, como mostra o enunciado (13).

Enfim, o entrelaçamento dos enunciados (11)-(14) mostra que a escrita, concebida como backup das línguas e dos saberes, vai deixando de ser uma ameaça e vai se tornando uma aliada na manutenção das línguas e dos conhecimentos indígenas, expresso de forma mais explícita nos enunciados (13) e (14).

Esta discussão mostra que o translinguajamento, de acordo com Gloria Anzaldúa (2012), não é uma habilidade, como o bilinguismo. O translinguajamento é um modo de viver e de estar no mundo, na travessia entre línguas. Translinguajar é criar rachaduras no projeto colonial, ainda vigente, é rasurar as normas da escrita e deixar vazar os pensamentos, os conhecimentos e os sentimentos ocultados pela colonialidade.

\section{Considerações finais}

Com as discussões embasadas pelos conhecimentos dos docentes indígenas, compartilhados nos enunciados (1)-(14), evidencia-se a percepção do estudo complementar Português Intercultural como uma das "práticas linguísticas culturais e luta por poder" (MIGNOLO, 2003, p. 310) da licenciatura em Educação Intercultural da UFG. Trata-se de mais um espaço para o protagonismo das línguas e das epistemologias indígenas.

No estudo complementar Português Intercultural, em que o português é concebido como língua de relações interculturais, o translinguajamento é a prática sociolinguística que atravessa a oralidade e a escrita. Assim, as práticas translinguajadoras fortalecem as lutas situadas em relações assimétricas de poder (HANKS, 2008) para além das dicotomias dominantes/dominados, opressores/oprimidos, centro/periferia (borda ou margem) etc. 0 Português Intercultural dialoga com a escrita em movimento translinguajador e enfrenta o desafio de interpenetrar (para interpretar) os sentidos e os significados construídos, na oralidade e na escrita, a partir dos pensamentos vivos e pulsantes e das epistemologias interculturais.

O tenso e conflituoso diálogo intercultural, nas relações de poder linguístico, não prescinde das estratégias de dominação das forças dominadoras. Por isso, os indígenas, situados na zona de colisão política, social e linguística, entre os muitos mundos que os cercam e que eles habitam, isto é, nos espaços de translinguajamento, fazem alianças com a sociedade não indígena. São alianças em que eles têm o controle da situação.

Os professores indígenas se apropriam das ideologias e das categorias metalinguísticas coloniais. Entretanto, por meio de práticas translinguajadoras, do pensar em e entre línguas, significam essas ideologias e essas categorias metalinguísticas a partir de suas epistemologias e thes dão sentido, com novos significados para esse "novo mundo" novo - o mundo nascido das travessias e das intersecções entre os pensamentos, as 
epistemologias e as línguas indígenas e as outras mais que os cercam. Eles reconceituam os conceitos coloniais, desde seus repertórios conceituais, com os significados construídos de dentro de seus pluriversos de referenciação (KOPENAWA; ALBERT, 2015).

No processo de reconfiguração das ideologias coloniais, 'escrita' e 'padrão linguístico', para além de convenções e normatizações, são entendidos como importantes aliados na luta política e social que os indígenas enfrentam em seu cotidiano. As normas não são normas, as convenções não são convenções. Ambas são instrumentos, são armas com as quais os indígenas se munem para "se virarem nesses dois mundos". Cada vez mais cercados pelo mundo não indígena. Por isso, é necessário e urgente fazer backup de seus conhecimentos, uma vez que os processos de updating são inevitáveis. Nesse caso, a escrita é de suma importância. Além disso, saber escrever "corretamente" em português é fundamental para "mandar para não indígena compreender melhor e gostar" e, assim, convencê-lo. A norma - escrever corretamente em português - não é um conjunto de regras a se obedecer, é uma forma de persuasão.

Por todo o exposto, consideramos que assumir a interculturalidade na formação de docentes indígenas, conforme a configuração resumida nesta discussão, significa desocultar a tensão e os conflitos históricos instaurados pela modernidade/colonialidade na América. Em outras palavras, significa desvelar as violências históricas que a educação escolar instaurou nos territórios coloniazados. Essas tensões e esses conflitos estão refletidos nas atitudes dos povos indígenas com relação ao português, no entendimento da importância de dominar essa língua, ainda que seja a língua pela qual a violência que promove o genocídio dos povos indígenas e a extinção de suas línguas entrou nesses territórios. Nesse sentido e nesse contexto, conceber o português como língua de relações interculturais e entender a apropriação do português pelo indígenas como letramento para sobrevivência é um ato político de independência civil e social desses povos.

\section{Referências}

ANZALDÚA, Gloria. Borderlands la frontera - the new mestiza. San Francisco: Aunt Lute Books, 2012.

BRANDÃO-TAPUIA, Welington Vieira. Concepção de Linguagem. Prática escrita em sala de aula de Português Intercultural. Licenciatura em Educação Intercultural. Núcleo Takinahakỹ de Formação Superior Indígena, Universidade Federal de Goiás, Goiânia, 2008.

BRASIL. Constituição da República Federativa do Brasil. Brasília: Casa Civil da Presidência da República, 1988.

BRASIL. Lei № 9.394 - Diretrizes e Bases da Educação Nacional. Brasília: Casa Civil da Presidência da República, [1996] 2017.

BRUPAHIDI-AKWẼ. Concepção de Linguagem. Prática escrita em sala de aula de Português Intercultural. Licenciatura em Educação Intercultural. Núcleo Takinahakỹ de Formação Superior Indígena, Universidade Federal de Goiás, Goiânia, 2015. 
COTRIM, Rodrigo Guimarães Prudente Marques. Inglês Intercultural - a leitura e a escrita indígena em contexto bi/tri/plurilíngue e intercultural = Intercultural English - indigenous Reading and writing in intercultural bi/tri/multilingual context. Goiânia: Gráfica UFG, 2017.

GINZBURG, Carlo. Mitos emblemas sinais: Morfologia e História. São Paulo: Companhia das Letras, 2016.

GOMES, Nilma Lino. O movimento negro e a intelectualidade negra descolonizando os currículos. In: BERNARDINO-COSTA, Joaze; MALDONADO-TORRES, Nelson; GROSFOGUEL, Ramón (Orgs.). Decolonialidade e pensamento afrodiaspórico. Belo Horizonte: Autêntica, 2018. p. 223-246.

HANKS, William F. Língua como prática social - das relações entre língua, cultura e sociedade a partir de Bourdieu e Bakhtin. (Trad. Bentes, A. C., Rezende, R. C., Machado, M. A. R.). São Paulo: Cortez, 2008.

JÃXY-KRAHÔ. Comunicação Oral. Documentação de Sala de Aula Intercultural - Povo Krahô. Licenciatura em Educação Intercultural. Núcleo Takinahakỹ de Formação Superior Indígena, Universidade Federal de Goiás, Goiânia, 2014.

KOPENAWA, Davi; ALBERT, Bruce. A queda do céu - palavras de um xamã yanomami. (Trad. Beatriz Perrone-Moisés). São Paulo: Companhia das Letras, 2015.

KUMRIZDAZÊ-XERENTE, C. S. Sustentabilidade cultural do povo Akwẽ Xerente sobre o aproveitamento de plantas frutíferas do cerrado. In: PIMENTEL DA SILVA, Maria do Socorro; BORGES, Mônica Veloso. Práticas pedagógicas de docentes indígenas. Goiânia: Cegraf/UFG, 2015. p. 153-162.

LARIWANA-KARAJÁ, Leandro. Concepção de bilinguismo e interculturalidade nas práticas de estágio do Curso de Licenciatura Intercultural de Formação Superior de Professores Indígenas da UFG. In: PIMENTEL DA SILVA, Maria do Socorro; BORGES, Mônica Veloso. Práticas pedagógicas de docentes indígenas. Goiânia: Cegraf/UFG, 2015, p. 311-320.

LIMA, Hildomar José de. Interpretação transemiótica de práticas escritas em português por pessoas surdas. 2020. $191 \mathrm{f}$. Tese (Doutorado em Letras e Linguística) - Programa de PósGraduação em Letras e Linguística, Faculdade de Letras, Universidade Federal de Goiás, Goiânia, 2020.

MAIRU-KARAJÁ, Eli. Memorial. Prática escrita em sala de aula de Português Intercultural. Licenciatura em Educação Intercultural, Núcleo Takinahakỹ de Formação Superior Indígena, Universidade Federal de Goiás, Goiânia, 2012.

MAKONI, Sinfree; PENNYCOOK, Alastair. Disinventing and (Re)Constituting Languages. Critical Inquiry in Language Studies: an Internacional Journal, v. 2, n. 3, p. 137-156, 2005. https://doi.org/10.1207/s15427595cils0203 1

MIGNOLO, Walter. D. Histórias locais/projetos globais: colonialidade, saberes subalternos e pensamento liminar. (Trad. Solange Ribeiro de Oliveira). Belo Horizonte: UFMG, 2003.

MIGNOLO, Walter. D. El pensamiento decolonial: desprendimiento y apertura. Un manifesto. In: CASTRO-GOMEZ, Santiago; GROSFOGUEL, Ramón. El giro decolonial - reflexiones para una diversidad epistémica más allá del capitalismo global. Bogotá: Siglo del Hombre 
Editores; Universidad Central, Instituto de Estudios Sociales Contemporáneos y Pontifícia Universidad Javeriana, Instituto Pensar, 2007. p. 25-46.

MIGNOLO, Walter D. Colonialidade: o lado mais escuro da modernidade. (Trad. Marco Oliveira). Revista brasileira de ciências sociais. [online], Rio de Janeiro, v. 32, n. 94, e329402, 2017. https://doi.org/10.17666/329402/2017

NEUMANN, Eduardo. Letra de Índios - cultura escrita, comunicação e memória indígena nas Reduções do Paraguai. São Bernardo do Campo: Nhanduti, 2015.

PENNYCOOK, Alastair. Language as a local practice. London/New York: Routledge - Taylor \& Francis Group, 2010.

PIMENTEL DA SILVA, Maria do Socorro. Reflexão político-pedagógica sobre educação bilíngue intercultural. In: ROCHA, Leandro Mendes; PIMENTEL DA SILVA, Maria do Socorro; BORGES, Mônica Veloso. (Eds.). Cidadania, interculturalidade e formação de docentes indígenas. Goiânia: PUC-GO, 2010. p. 11-17.

PRUNÕTRI-AKWẼ, C. Concepção de Linguagem. Prática escrita em sala de aula de Português Intercultural. Licenciatura em Educação Intercultural, Núcleo Takinahakỹ de Formação Superior Indígena, Universidade Federal de Goiás, Goiânia, 2015.

QUIJANO, Aníbal. Colonialidade do poder e classificação social. In: SANTOS, Boaventura de Sousa; MENESES, Maria Paula. (Eds.). Epistemologias do Sul. Coimbra: Almedina, 2010. p. 73116.

REZENDE, Tânia Ferreira. Entre a senzala, o tijupá e a escola: a questão linguístico-identitária entre as/os tapuia do Carretão-Goiás. In: Congresso Luso-Afrobrasileiro de Ciências Sociais, 11, 2011, Salvador. Anais do XI Congresso Luso-Afrobrasileiro de Ciências Sociais. Salvador: XI CONLAB, 2011, p. 1-16.

REZENDE, Tânia Ferreira. (Org.). Literatura em contexto de interculturalidade. Goiânia: Cegraf/Funap, 2013.

REZENDE, Tânia Ferreira. Praticar a escrita em português intercultural com os indígenas da região Araguaia-Tocantins. In: PIMENTEL DA SILVA, Maria Silva; BORGES, Mônica Veloso. (Orgs.). Educação Intercultural - experiências e desafios políticos pedagógicos. Goiânia: Prolind/Secad-MEC/Funape, 2013. p. 169-191.

REZENDE, Tânia Ferreira. Políticas de apagamento linguístico em contexto brasileiro. In: BARROS, Débora Magalhães de; SILVA, Kleber Aparecido da; CASSEB-GALVÃO, Vânia Cristina. (Orgs.). O ensino em quatro atos: interculturalidade, tecnologia de informação, leitura e gramática. Campinas: Pontes, 2015. p. 63-77.

ROCHA, Leandro Mendes; PIMENTEL DA SILVA, Maria do Socorro; BORGES, Mônica Veloso. (Orgs.). Cidadania, interculturalidade e formação de docentes indígenas. Goiânia: PUC-GO, 2010.

RODRIGUES-TAPUIA, Eunice da Rocha Moraes. Processo sócio-histórico de formação do Português Tapuia. 2011, 87 f. Trabalho de Conclusão de Curso (Licenciatura em Educação Intercultural-Ciências da Linguagem). Núcleo Takinahakỹ de Formação Superior Indígena, Universidade Federal de Goiás, Goiânia, 2011. 
RODRIGUES-TAPUIA, Eunice Moraes da Rocha. Português Tapuia: um signo de resistência indígena. Porto das Letras, Porto Nacional, Dossiê Sociolinguística: os Olhares do Sul na Desestabilização dos Modelos Herdados, v. 4, n. 1, p. 133-154, 2018.

SPIVAK, Gayatri Chakravorty. Pode o subalterno falar? (Trad. Almeida, S. R. G., Feitosa, M. P. Feitosa, A. P.). Belo Horizonte: UFMG, 2010.

TSERERUOTZE'Õ-A'UWẼ. Concepção de Linguagem. Prática escrita em sala de aula de Português Intercultural. Licenciatura em Educação Intercultural, Núcleo Takinahakỹ de Formação Superior Indígena, Universidade Federal de Goiás, Goiânia, 2015.

VIEIRA-TAPUIA, Luís Antônio. Práticas escritas interculturais na comunidade Tapuia do Carretão-GO. Projeto de Pesquisa Extraescolar (Licenciatura em Educação Intercultural), Núcleo Takinahakỹ de Formação Superior Indígena, Universidade Federal de Goiás, Goiânia, 2012.

WALLERSTEIN, Immanuel. The modern world-system. San Diego/New York: Academic Press, Tomo I, 1974.

Recebido em: 20/04/2020.

Aceito em: 27/05/2020. 